\title{
Aspectos metodológicos convergentes entre dois campos de criação, Design de Produto e Design de Interiores
}

\author{
Convergent methodological aspects between two fields of creation, Product Design \\ and Interior Design
}

OLIVEIRA, Gilberto Rangel de; D.Sc.; Pontifícia Universidade Católica do Rio de Janeiro - PUC-Rio. grangeldesign@gmail.com

MONT'ALVÃO, Claudia; D.Sc.; Pontifícia Universidade Católica do Rio de Janeiro - PUC-Rio.

cmontalvao@puc-rio.br

\section{Resumo}

O processo de trabalho do designer e do designer de interiores possui algumas peculiaridades em comum das quais destaca-se a exigência do conhecimento sólido de projeto. $O$ desenvolvimento de um projeto pressupõe o uso de um método. Através da análise entre uma estrutura geral de método em design defendida por Nigel Cross (2008) e de dois métodos de design de interiores, este artigo apontará as convergências entre os métodos de projeto das duas atividades e as ferramentas mais utilizadas na investigação da natureza do problema de projeto. No final serão apontados elementos essenciais que permeiam as duas atividades, com ênfase ao método de projeto de interiores.

Palavras Chave: metodologia de projeto; método design produto; método projeto de interiores.

\section{Abstract}

The design process of the designer and the interior designer has some peculiarities in common of which stands out, the requirement of solid project knowledge. The process of developing a project presupposes the practice of a design method. Through the analysis of a general design method structure defended by Nigel Cross (2008) and two interior design methods, this article will point out the convergences between the design methods of the two activities and the most used tools in the investigation of the nature of the problem. At the end will be pointed out essential elements that permeate the two activities, with emphasis on the method of interior design.

Keywords: methodology project; method design process; method interior design.

\section{Introdução}

A atividade de design de interiores (como é entendida atualmente) estabeleceu-se em meados do século XVIII construindo um elo de interseção entre a arquitetura e o design, conforme alguns autores defendem. A origem da própria atividade está ligada à formação em arquitetura, afinal, a grande maioria dos primeiros designers de interiores eram arquitetos. Por outro lado, 0 design de interiores tem alcançado posições cada vez mais sólidas, com significativa expressão no mercado de trabalho, fato este que serviu como parte de justificativa para recente regulamentação da profissão através do projeto de Lei 13.369/2016. Conforme definido pela regulamentação da profissão, "o designer de interiores e ambientes é o profissional que planeja e projeta espaços internos, visando ao conforto, à estética, à saúde e à segurança dos usuários, respeitadas as 
atribuições privativas de outras profissões regulamentadas em lei." Face o exposto, fica evidente a importância do uso de métodos de projeto sólidos e fundamentados a fim de atingir os objetivos atribuídos à atividade. Neste sentido, algumas tentativas têm ocorrido no intuito de contribuir com este objetivo.

Neste artigo serão expostos dois métodos de projeto para interiores e a relação de semelhança destes com a estrutura metodológica do Design. O primeiro o Método de Planejamento do Prof. Mark Karlen (2008), apresenta etapas bem definidas na fase de levantamento (construção do briefing e elaboração de proposta) e o segundo é o método proposto recentemente por Oliveira \& Mont'Alvão (2016), o qual apresenta uma estrutura metodológica robusta, com fases e subfases, amparada nos princípios da ergonomia do ambiente construído, e foi elaborado a partir de demanda identificada em pesquisa descritiva com profissionais da área e usuários deste tipo de serviço. Serão apontadas semelhanças entre a estrutura metodológica para o Design proposta por Cross (2008) e os métodos de design de interiores tratados. O artigo propõe-se a demonstrar ao leitor que os princípios metodológicos nos processos de criação possuem uma "identidade" genuína e apresentam técnicas semelhantes, resguardando-se as diferenças intrínsecas de cada atividade e os contextos os quais os métodos são aplicados.

\section{Método e Metodologia}

Ao se falar de método, de imediato pensa-se em algo organizado com qualidade, ou seja, um trabalho "com método". Neste caso apenas estamos nos referindo a palavra método enquanto adjetivo. Coelho (2008, p. 251) explica que "o substantivo método chega-nos do latim methodus, que provém da locução grega meta (meta) + hodos (caminho). Seria então, o caminho para se atingir uma finalidade". $\mathrm{O}$ autor completa:

Normalmente, o termo método vem associado a outros termos, como PROCESSO e TÉCNICA. Entendemos processo, este sim, como o caminho em si, composto de fases, por onde o método percorre. [...] De fato, o processo seria um método em movimento. Já a técnica, seria como que o método cristalizado e, em geral, compreende ação menos complexa em termos de procedimentos envolvidos. É mais fácil entender o método como um composto de várias TÉCNICAS". (COELHO, 2008 p. 252)

Em termos aplicados, o termo método associa-se a denominações ligadas à natureza do objeto do trabalho, como é o caso método de projeto. Roozenburg \& Eekels (1995), no seu livro Product Design: Fundamentals and Methods (Design de Produto Fundamentos e Métodos) apresentam uma explicação clara e direta sobre o assunto: "Metodologia de projeto é a ciência dos métodos que são ou que podem ser aplicados no projeto" ${ }^{1}$. Os autores evidenciam os dois significados que podem ser abordados no estudo sobre metodologia, na língua inglesa (assim como na língua portuguesa) da palavra "metodologia".

O primeiro significado é: a ciência ou o estudo do método, ou seja, a descrição, explicação e avaliação de métodos. O segundo significado de "metodologia" é: um corpo de métodos, procedimentos, conceitos e regras de trabalho empregadas por uma ciência particular, arte ou disciplina. Nos círculos acadêmicos, o termo "metodologia" normalmente tem o primeiro

1 Design methodology is the science of methods that are or can be applied in designing (Roozenburg \& Eekels, 1995 p. 29). Tradução do autor. 
significado, ou seja, um campo de estudo e pesquisa² (ROOZENBURG \& EEKELS, 1995, p. 29).

Coelho (2008, p. 255) lembra que em alguns casos o uso da palavra metodologia no meio acadêmico costuma ter diferentes denominações, com ênfase ao "campo teórico de determinada área ou concentrando-se em grandes áreas, como é o caso de disciplinas que trabalham conteúdos a partir das ciências biológicas, sociais, humanas ou físicas". Os estudos realizados nessas pesquisas costumam contemplar tanto a teoria metodológica em si, quanto sua aplicação em objetos específicos (metodologia aplicada). Neste caso, o estudo de disciplinas com esse entendimento privilegia a chamada metodologia científica "embora trabalhem, por vezes, com procedimentos metodológicos particulares a um campo delimitado".

É o caso, por exemplo, do curso de Design, em que o chamado método projetual é ensinado. Justifica-se esse tipo de tratamento da disciplina sobre métodos no ensino do design em FUNÇÃO de peculiaridades da profissão, que exige conhecimentos sólidos de PROJETO (COELHO, 2008, p. 255).

Bonsiepe (2012), no seu livro Design: como prática de projeto, corrobora com a corrente de pensamento sobre semelhanças entre o processo de projeto e o processo de investigação científica. "A formulação de uma hipótese científica corresponde no âmbito do projeto, ao briefing, contendo descrição dos requisitos funcionais, tecnológicos, econômicos, sociais e culturais da proposta."

Nessa linha de pensamento sobre o processo de projeto, Bonsiepe (2012) defende que se trata de uma "operação estruturalista" com o objetivo de montar o "esqueleto da atividade de projeto". O autor acrescenta de forma crítica que, desde a primeira geração dos metodólogos do Design, tentou-se - e ainda tentam - "explicitar e modelar o processo de projeto e, por outro lado, fazer uma descrição de técnicas específicas, assemelhando-se a uma receita culinária para o projetista".

Para essa finalidade utilizaram-se das contribuições de algumas disciplinas científicas: a Teoria dos Conjuntos, a Teoria de Sistemas, a Teoria da Informação e a Teoria da Tomada de Decisões, entre outras. Inicialmente predominavam as disciplinas matemáticas e aquelas que, no jargão acadêmico, são chamadas de "duras", mas nos últimos anos observa-se um movimento para as ciências chamadas "brandas", tais como a Psicologia Ambiental e a Teoria Psicanalítica dos Símbolos (BONSIEPE, 2012, p. 92).

O autor defende que as metodologias elaboradas até o momento são caracterizadas por uma "tendência a afastar-se da esfera da Arte e aproximar-se da esfera da atividade científica". Contudo, é categórico em afirmar: "O Design Industrial não é e nem será uma ciência, embora não exclua as interações frutíferas entre diversas áreas". (Ibidem)

Argan (1993, p. 156) esclarece que a metodologia de projeto é muito mais que "um método para produção arquitetônica". O autor explica que é "possível conceber um programa expresso com palavras, com cifras, ao passo que o projeto já é uma imagem feita visando uma execução técnica". A partir dessa conotação fundamental, pode-se dizer que o desenho (o projeto) é a relação direta entre uma atividade puramente intelectual e uma atividade manual.

O projeto visa objetivamente permitir a interpretação e posterior avaliação da proposta

2 In English the word "methodology" has two meanings. The First meaning is: a science or study of method, i.e., the description, explanation and valuation of methods. The second meaning of "methodology" is: a body of methods, procedures, working concepts and rules employed by a particular science, art or discipline. In academic circles the term "methodology" normally has the first meaning, i.e. a field of study and research (Ibidem). Tradução do autor. 
imaginada pelo arquiteto, além de permitir a previsão de custos e tempo exigidos para a edificação da obra, além dos aspectos legais. Silva (1998) define seu entendimento sobre projeto arquitetônico:

Projeto arquitetônico é uma proposta de solução para um particular problema de organização do entorno humano, através de uma determinada forma construtiva, bem como a descrição desta forma e as prescrições para sua execução (Ibidem, p. 39).

Na definição do autor entende-se que o projeto arquitetônico visa atender uma necessidade particular em benefício do homem, de forma realizável, exequível, no qual se prevê que estará prescrito todo detalhamento para execução. Nesse sentido, a definição de Silva (1988) envolve cinco entidades: 1) o problema particular de organização do entorno humano, sinteticamente traduzido no programa; 2) a solução; 3) a forma construtiva, eventualmente convertida em obra; 4) a descrição da forma; e 5) o conjunto de prescrições para sua execução.

Os autores mencionados nesse conciso apontamento sobre metodologia de projeto defendem amplamente o uso de uma metodologia adequada para o desenvolvimento de projetos. Apesar de os termos ganharem diferentes conotações em contextos e autores diversos, mais importante do que adotar esta ou aquela palavra: processo, técnica e método, é perceber que, em termos metodológicos o projeto envolve uma elaboração complexa de ações previamente planejadas e definidas, combinadas a outras nem sempre conscientes, que vão ganhando forma durante o processo de trabalho.

\section{Processos metodológicos do Design}

A adoção de métodos científicos aliada à prática de projeto na área do design remonta aproximadamente à década de 1950, quando o Design rompeu alguns vínculos importantes que ainda mantinha com a tradição artística na produção de artefatos. A primeira geração de métodos de projeto foi baseada na aplicação de métodos racionais e sistemáticos, "científicos", e a segunda geração se afastou das tentativas para otimizar e da onipotência do designer (especialmente para "wicked problems" - problemas perniciosos), para o reconhecimento de soluções satisfatórias ou adequadas. $^{3}$

Cross (2008, p. 29) explica que houve muitas tentativas para elaborar mapas ou modelos do processo de design - modelos descritivos. Os modelos de processo em design geralmente são desenhados na forma de diagrama de fluxo, com o desenvolvimento em fases, loops de retorno. Em alguns casos esses modelos simplesmente descrevem as sequências de atividades que normalmente ocorrem na fase de concepção de projeto.

Os modelos descritivos do processo de design geralmente identificam o significado de propor um conceito solução no início do processo, refletindo a natureza "centrada na solução" do pensamento do design. Esta solução inicial de "conjectura" é submetida a análise, avaliação, refinamento e desenvolvimento. [...] O processo é heurístico: usando a experiência anterior, diretrizes gerais e "regras básicas" que levam ao que o designer

\footnotetext{
${ }^{3}$ Foi publicada uma detalhada revisão sobre a primeira e segunda geração de metodólogos do Design Industrial mundial, em: Oliveira, Gilberto Rangel de; Mont'Alvão, Cláudia; "REVISÃO DOS MÉTODOS DE DESIGN INDUSTRIAL NO FINAL DO SÉCULO XX E O CONTEXTO SÓCIOECONÔMICO BRASILEIRO", p. 1331-1343 . In: Anais do 120 Congresso Brasileiro de Pesquisa e Desenvolvimento em Design [= Blucher Design Proceedings, v. 9, n. 2]. São Paulo: Blucher, 2016. ISSN 2318-6968, DOI 10.5151/despro-ped2016-0113
} 
espera ser a direção certa, mas sem garantia absoluta de sucesso. (CROSS, 2008 p. 29)

O autor aponta que o resultado final do processo é a comunicação do projeto pronto para fabricação. Antes disso, a proposta de projeto está sujeita a avaliação em relação aos objetivos, restrições e critérios do briefing inicial. Os modelos do processo de design "Dispondo os quatro tipos de atividade em sua sequência natural, temos um modelo simples de quatro estágios do processo de projeto consistindo em: exploração; geração; avaliação; e comunicação". (Ibidem, p. 30).

Além de modelos que simplesmente descrevem um processo de projeto mais ou menos convencional e heurístico, houve várias tentativas de construção de modelos prescritivos do processo de design. Eles costumam ser considerados como uma metodologia de design particular que enfatizam a necessidade de uma fase analítica para processar a geração de soluções conceitos, através da compreensão "real" do problema de projeto.

No sentido de apontar as fases mais significativas no processo metodológico do design, apoiase nas assertivas de Cross (2008 p.35 e 36) que aponta para um modelo descritivo mais detalhado desenvolvido por Archer (1984). Este modelo inclui interações com o mundo exterior do próprio processo de design como, entrada de clientes, treinamento e experiência do designer, ou outras fontes de informação, etc. A saída (output) é, claro, a comunicação de uma solução específica. 0 diagrama de fluxo é dinâmico e apresenta entradas, saídas e feedbacks. Cross (2008 pg .36) descreve as seis etapas propostas por Archer (1984):

- Programação - estabelece questões cruciais, propõe um curso de ação;

- Coleta de dados - coleta, classificação e armazenamento de dados;

- Análise - identifica subproblemas, prepara especificações de desempenho, reavalia o programa proposto;

- Síntese - prepara propostas design mais significativas;

- Desenvolvimento - desenvolvimento de protótipos, preparação e execução de estudos de validação;

- Comunicação - prepara documentação de fabricação.

Considera-se que na maioria das situações de design não é possível tentar analisar o problema, separado de soluções conceituais. O modelo de Archer (1994) tenta capturar a natureza essencial do processo de design, na qual a compreensão do problema e da solução se desenvolve em conjunto, ou evolui de forma conjunta. O modelo também tenta reconhecer que não há um padrão esperado de progressão no processo de design, de um determinado problema a uma solução proposta.

\section{Processos metodológicos do Design de Interiores}

Brooker e Stone (2014, p. 12) explicam que o design de interiores (ou projeto de interiores) ${ }^{5}$ é uma atividade multidisciplinar que envolve a criação de ambientes internos que articulam o clima

\footnotetext{
${ }^{4}$ Descriptive models of the design process usually identify the significance of generating a solution concept early in the process, thus reflecting the "solution-focused" nature of design thinking. This initial solution "conjecture" is then subjected to analysis, evaluation, refinement, and development. The process is heuristic: using previous experience, general guidelines and "rules of thumb" that lead in what the designer hopes to be the right direction, but with no absolute guarantee of success. (CROSS, 2008 p. 29). Tradução livre do autor.

${ }^{5}$ No caso da atividade-fim - o projeto, os arquitetos e urbanistas costumam adotar a nomenclatura projeto de interiores e/ou arquitetura de interiores, ou projeto de reforma de interiores (conforme verificado em norma da CAU - Conselho
} 
e a identidade por meio da manipulação dos volumes espaciais, da colocação de elementos específicos e mobiliário, além do tratamento das superfícies. "Em geral, descreve projetos que requerem poucas mudanças estruturais - ou nenhuma - na construção já existente, embora haja muitas exceções". O espaço é mantido em seu estado estrutural original e o novo interior é nele inserido. Neste artigo corrobora-se os argumentos dessa definição e suas consequências.

Os autores fazem também uma distinção entre os termos decoração de interiores e arquitetura de interiores. O primeiro trata-se da arte de decorar espaços interiores - cômodos ou ambientes - para transmitir uma identidade característica que funciona bem com a arquitetura existente. Está relacionada com padrões de superfícies, ornamentos, mobiliário, acessórios, iluminação e materiais. O segundo termo preocupa-se com a remodelagem das construções e atitudes direcionadas para os espaços e as estruturas existentes, a reutilização de construções e os princípios organizacionais. A arquitetura de interiores conecta as práticas do design de interiores com a arquitetura, e com frequência inclui problemas complexos estruturais, ambientais e técnicos. (Ibid. p. 11 e 12)

Higgins $(2015$, p. 6) lembra que o design de interiores se dedica à "criação de interfaces entre as pessoas e as edificações que elas usam. Como resultado, o designer de interiores precisa considerar uma série de questões, que tanto podem se relacionar com a estratégia de projeto como com os detalhes". Nesse sentido, a estratégia a ser utilizada demanda o uso de métodos de projeto que auxiliem o profissional com o objetivo de contribuir para o desenvolvimento de suas atividades, a fim de alcançar melhores resultados.

O Prof. Mark Karlen, do Programa de Mestrado em Belas Artes - Arquitetura de Interiores do Moore College of Art \& Design, Filadélfia - Pensilvânia, EUA reforça o argumento para o uso de métodos de projeto para a atividade de design de interiores:

Do ponto de vista prático e profissional o arquiteto precisa de um processo eficiente e confiável ao qual recorrer sempre que se deparar com um projeto de arquitetura de interiores. Reunir alguns fatos básicos e ficar olhando para uma planta baixa em branco até que a inspiração surja é uma abordagem totalmente inviável. (KARLEN, 2008 p. 16)

O autor defende uma Metodologia de Planejamento que se refere a etapa do processo de planejamento espacial que se inicia assim que "os problemas de projeto são apresentados ao projetista (com ou sem um programa de necessidades) e que termina quando o planejamento físico começa - geralmente, com organogramas ou plantas baixas esquemáticas". Segundo o autor o processo básico de elaboração de um programa de necessidades para projeto composta pelos seguintes passos:

1. Entrevista - nível executivo; nível administrativo; nível operacional.

2. Observação em campo - observação acompanhada; observação não intrusiva; inventários do mobiliário e equipamentos preexistentes (se forem reaproveitados).

3. Estabelecer os parâmetros de arquitetura - colete todos os dados preliminares para projeto (incluindo instalações hidro sanitárias e elétricas); colete dados contextuais (arquitetônicos, históricos, sociais); pesquise os condicionantes legais (plano diretor, e/ou código de edificações).

\footnotetext{
de Arquitetura e Urbanismo). Já o MEC - Ministério da Educação e Cultura instituiu o termo design de interiores no final da década de noventa, dando ênfase ao termo design para a atividade, e por decorrência, à designação do profissional como designer de interiores, conforme aprovado pelo PL 13.369/2016 recentemente.
} 
4. Organizar os dados coletados (programa de necessidades preliminar) - organize os dados no formato sequencial mais adequado par ao planejamento; resuma os fatores quantitativos confirmados (área de piso, área interna e total, tamanhos dos equipamentos, etc.).

5. Estudar as incógnitas - reúna informações detalhadas sobre os processos e os equipamentos; reúna informações de estudos de caso sobre equipamentos semelhantes; integre os dados pesquisados ao programa preliminar.

6. Analisar os dados - descubra as afinidades de planejamento (inter-relações profissionais, zoneamento público / privado, necessidades especiais de acústica, etc.); descubra as afinidades de horários (maximize o uso do espaço); identifique as relações de planejamento ou arquitetura (terreno, condições, estruturais, hidro sanitárias e elétricas).

7. Interpretar e organizar os dados em um diagrama (programa de necessidades completo) - defina os problemas funcionais em termos de planejamento; estabeleça uma abordagem conceitual básica (em termos de objetivos humanos/e de imagem/estéticos); elabore diagramas de relações ou adjacências (para visualização do cliente e do arquiteto).

8. Sintetizar os dados (documento completo) - finalize os conceitos do projeto - DEFINA O PROBLEMA; defina e registre parâmetros para as questões orçamentárias básicas; prepare um pacote para ser aprovado pelo cliente e para ser usado como manual de planejamento espacial do projetista. (KARLEN, 2008, p 14 e 15).

A metodologia de planejamento encerra-se quando se inicia o planejamento físico e o desenvolvimento de plantas baixas, com todas as implicações espaciais e projetuais diversas - é a fase do planejamento de espaços e plantas baixas esquemáticas. É natural que o programa de necessidades sofra algumas adequações por conta de novos conceitos, relações e necessidades não identificadas na primeira fase.

A fim de aprofundar a discussão sobre os aspectos metodológicos convergentes entre o Design Industrial e o Design de Interiores, apresenta-se o Método de Projeto para Interiores, proposto por (Oliveira \& Mont'Alvão, 2016) que possibilita conduzir o profissional por todas as fases do projeto: do planejamento inicial a elaboração espacial até a execução. Este método foi concebido a partir do resultado de pesquisa descritiva com um número expressivo de profissionais de design de interiores atuantes (voz do contratante) e com usuários (voz daquele que contrata) que implantaram projetos concebidos após a prestação de serviço realizada. ${ }^{6}$ Para propor uma nova metodologia, os dados da pesquisa foram avaliados sob o olhar dos princípios da ergonomia do ambiente construído e das estruturas metodológicas mais utilizadas na elaboração de projetos de interiores.

A partir dos resultados alcançados com a pesquisa - aspectos positivos e negativos, partiu-se para a elaboração do Método de Projeto de Interiores, que na sua concepção priorizou contemplar os seguintes aspectos: (1) processo sistematizado de fases e etapas; (2) detalhar o uso de ferramentas (ou técnicas) que melhor contribuam com a identificação das necessidades do usuário;

\footnotetext{
${ }^{6}$ O detalhamento da pesquisa descritiva e os resultados obtidos, bem como seus desdobramentos podem ser consultados através da publicação: DE OLIVEIRA, Gilberto Rangel; MONT'ALVÃO, Claudia Renata. O PROCESSO DE PROJETO DE INTERIORES E O USO DA ERGONOMIA NA PRÁTICA SEGUNDO A VISÃO DE PROFISSIONAIS E USUÁRIOS. Revista ErgodesignHCI, [S.I.], v. 5, n. Especial, p. 61 - 72, jan. 2017. ISSN 2317-8876. Disponível em: <http://periodicos.puc-rio.br/index.php/revistaergodesign-hci/article/view/351>. Acesso em: 21 mar. 2018. doi: http://dx.doi.org/10.22570/ergodesignhci.v5iEspecial.351.
} 
(3) agregar o conhecimento da ergonomia do ambiente construído; (4) realizar etapas de validação; (5) estabelecer pontos de loop e feedback. As etapas estruturais do método proposto estão representadas através do esquema gráfico geral Fig. 01.

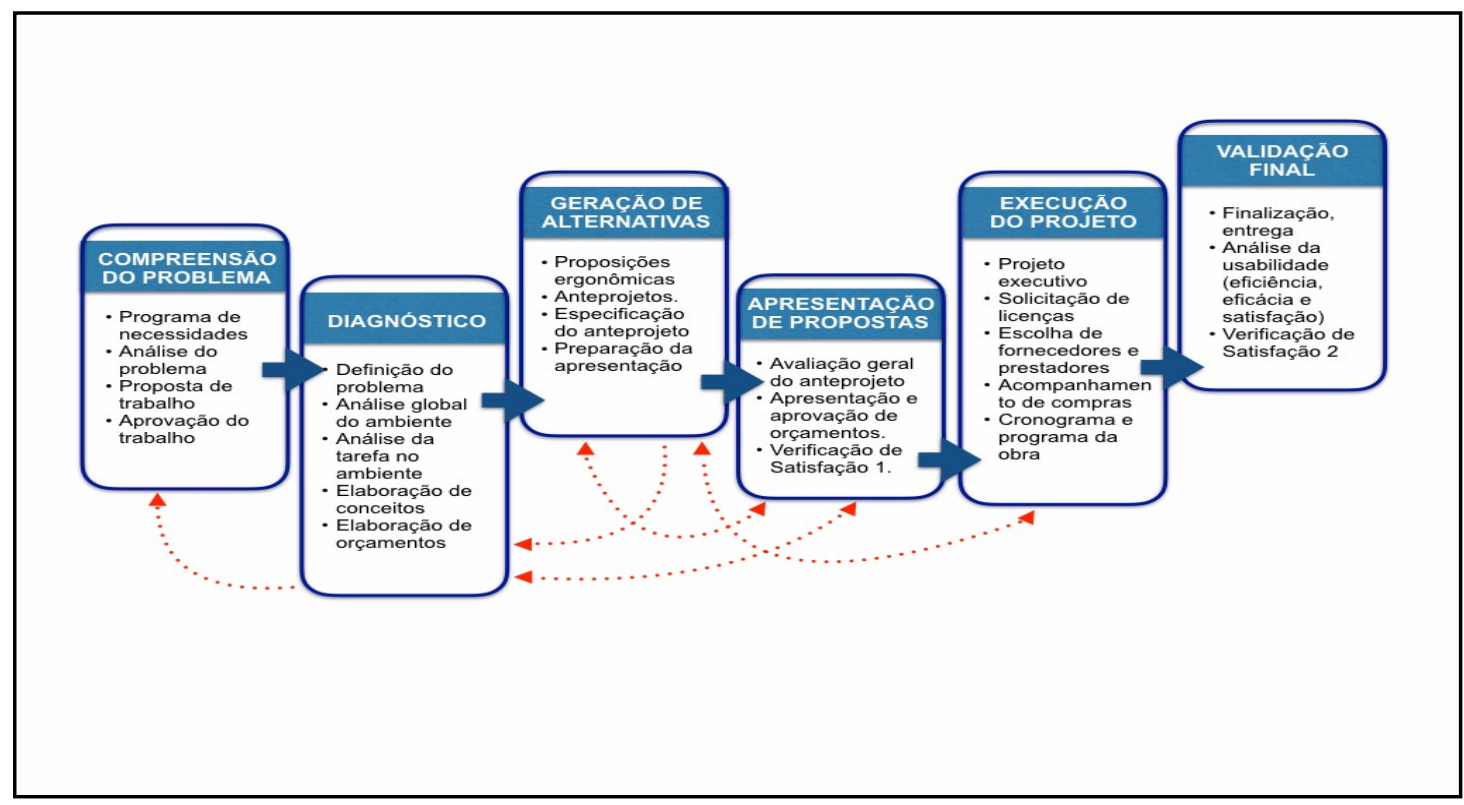

Fig. № 01 - Estrutura geral do método para o projeto de interiores. Fonte: o autor.

As etapas propostas para o método de projeto de interiores estão distribuídas em seis etapas principais e várias sub etapas. Cada atividade segue o fluxo contínuo da execução do próprio projeto, originando-se a partir da demanda proposta pelo usuário, passando pela fase de compreensão do problema, diagnóstico, geração de alternativas, apresentação de propostas, execução do projeto e validação. Cada etapa depende essencialmente dos resultados obtidos na fase anterior. Sendo assim, caso seja identificada alguma falha na realização de uma das atividades, faz-se necessário retomar a atividade anterior para correção do percurso. O método propõe uma sequência de fases que garantem ações com possibilidades de retorno. Cada fase ocorre numa sequência natural de execução, contudo respeitando a dinâmica do processo com suas idas e vindas. Os loops (retornos, destacados na linha tracejada) são essenciais para a realização de revisões das etapas e ajustes constantes na execução do projeto durante todo percurso do trabalho.

A etapa inicial para o método proposto para projeto de interiores é a COMPREENSÃO do PROBLEMA (Fig. № 02 - Etapa 1. Compreensão do Problema). Esta fase é essencial para o profissional perceber, entender e aprofundar a compreensão sobre o problema de projeto proposto e suas interveniências.

Busca-se compreender as necessidades dos usuários. As técnicas sugeridas para esta etapa são: entrevista estruturada + uso de questionário (check-list), visita técnica - observação assistemática. O profissional, se desejar, poderá lançar mão de desenhos, esboços e apresentar ou solicitar aos usuários fontes de informações adicionais, como sítios de internet, revistas, imagens, trabalhos executados anteriormente etc. Todas as informações extraídas devem ser registradas preferencialmente através de áudio e/ou anotações - que devem ficar adequadamente arquivadas. 


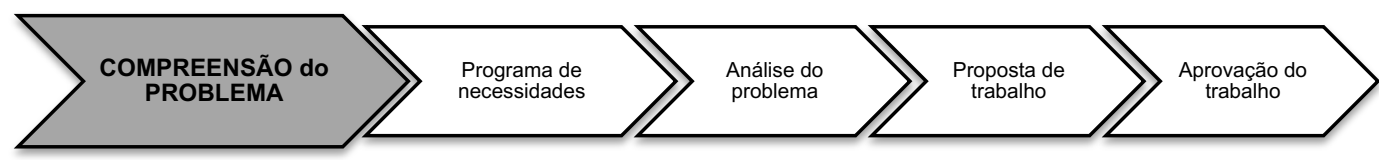

Fig. № 02 - Etapa 1- Compreensão do Problema. Fonte: o autor.

A segunda etapa do método para projeto de interiores é o DIAGNÓSTICO (Fig. № 03 - Etapa 2. Diagnóstico). A origem do nome é recorrente dos métodos de ergonomia e, conforme o próprio nome anuncia, pretende-se traçar o diagnóstico do problema. Pretende-se nesta etapa aprofundar o entendimento sobre os problemas a serem elucidados com o projeto de interiores, analisar o ambiente em que será executado o trabalho; realizar a análise da tarefa, estabelecer conceitos para o projeto e levantar os orçamentos iniciais para elaboração da planilha de custo primária de execução do projeto.

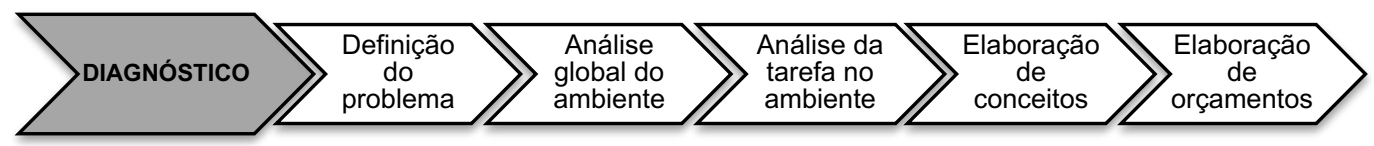

Fig. № 03- Etapa 2 - Diagnóstico. Fonte: o autor.

(1) Definir o problema de projeto não é algo simples. Nem sempre o usuário consegue expor para o profissional exatamente o que pretende alcançar com a realização do projeto. O profissional deve lançar mão de toda sua experiência, habilidade e atenção para obter as respostas sobre o problema proposto. (2) A análise global do ambiente é uma etapa que se inspira no método MEAC ${ }^{7}$ de análise do ambiente construído. Para avaliação do ambiente deve-se verificar todos os dados do ambiente, tais como: dimensionamento, iluminação, ventilação, ruído, temperatura, fluxos, layout, deslocamentos, materiais de revestimento e condições de acessibilidade. O levantamento é realizado através de anotações, observações, instrumentos de medição e registro fotográfico. (3) $A$ análise da tarefa cuida da observação do ambiente em uso visando identificar a usabilidade, ou seja, o quanto o espaço em uso atualmente é um facilitador ou o quanto é dificultoso para desenvolvimento das atividades que nele se abrigam.

A análise da tarefa compreende observar o sistema homem-tarefa-máquina-ambiente através da observação assistemática (ou sistemática, para tarefas mais complexas) das atividades e realizar registros de comportamento em situações reais de uso. Sugere-se o uso de gravações através de vídeo (para tarefas mais complexas), entrevista semiestruturada com o usuário, verbalização (depoimentos do usuário sobre seu modus operandi) e observação assistemática ou não estruturada. (4) A elaboração de conceitos faz parte da etapa criativa que deve ser trabalhada nesta fase, imediatamente após a definição do problema e a realização das análises. Faz-se necessário que o designer de interiores planeje qual conceito de projeto pretende implantar na sua

\footnotetext{
${ }^{7}$ A Metodologia Ergonômica de Avaliação para o Ambiente Construído - MEAC, Villarouco (2007), foi apresentada em mesa redonda no I ENEAC - Encontro Nacional sobre Ergonomia do Ambiente Construído e II Seminário Brasileiro de Acessibilidade Integral, realizado em Recife-PE.
} 
proposta e de que forma esse aspecto identifica-se com o usuário. A elaboração de um bom conceito de projeto proporciona projetos inovadores e alta característica de personalização, o que revela muita criatividade por parte do profissional. (5) Finalizando-se a segunda etapa do método proposto para projeto de interiores, o profissional deve levantar os orçamentos quantitativos primários para realização do projeto. Os orçamentos contemplam verificação de licenças, impostos, execução de obra civil, fornecimento de elementos para a obra, fornecimento de mobiliário e equipamentos, prestadores de serviços, etc. Esta etapa muitas vezes é condicionante para que o projeto siga em frente.

A terceira fase, GERAÇÃO DE ALTERNATIVAS, dependerá essencialmente do resultado da fase anterior (Fig. № 04 - Etapa 3. Geração de alternativas). Quanto melhor diagnosticado o problema de projeto, melhores chances de acertos o profissional poderá obter através das alternativas propostas. É uma etapa essencialmente de planejamento e criatividade, muito semelhante aos processos de projeto de design industrial e arquitetura. Esta fase inicia-se com as proposições ergonômicas - termo utilizado na MEAC (Villarouco, 2008), a qual sugere recomendações ergonômicas para o ambiente relacionadas a cada um dos problemas individualmente, e depois agrupados e relacionados entre si.

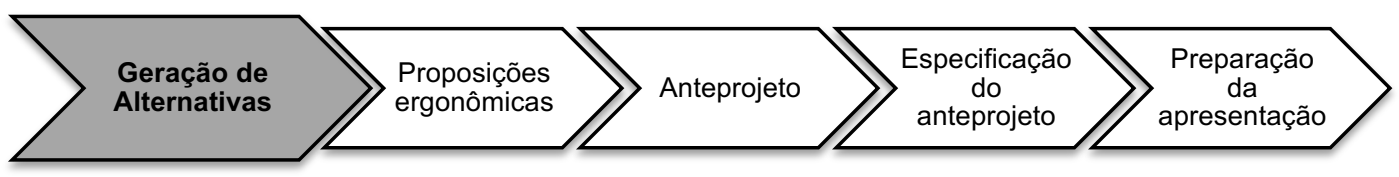

Fig. № 04 - Etapa 3 - Geração de alternativas. Fonte: o autor.

O profissional de interiores nas (1) proposições ergonômicas, deverá considerar possíveis soluções, planejando de forma individualizada a interação entre os elementos do ambiente. Por exemplo, a organização do layout para os armários de uma cozinha deve atender às necessidades do usuário, considerando os aspectos ergonômicos (acessibilidade, facilidade de uso, alcance, etc.). O (2) anteprojeto deverá considerar as proposições ergonômicas e todos os aspectos levantados no diagnóstico. Naturalmente, nem sempre é possível equacionar todos os problemas com uma solução única. Trata-se de um desafio permanente a busca por soluções que atendam ao maior número possível de respostas, considerando as questões identificadas e tratadas na Etapa 1 compreensão do problema. O anteprojeto deverá acompanhar o máximo de informações, que deverão ser apresentadas ao cliente. A escolha da proposta final irá apontar quais as prioridades a serem atendidas pelo projeto. Para a segunda atividade, (3) especificação do anteprojeto, deverá ser escolhida uma proposta definitiva. Dedica-se muito tempo para realização dessa etapa. 0 recomendado é que seja investido o tempo necessário para a especificação mais detalhada possível. Deve-se incluir especificação de elementos do ambiente, definição de cores, acabamentos, revestimentos, texturas, etc. O profissional deverá cercar-se de amostras de materiais e outros elementos dos fornecedores para apresentar a composição cromática planejada para o espaço e, naturalmente, o detalhamento técnico do projeto. A (4) preparação da apresentação deve ser uma etapa planejada de forma correta. Para a correta compreensão da proposta de projeto o demandador deve disponibilizar tempo e local adequados para esta atividade. Este momento deve ser marcado pela qualidade das informações passadas e pela própria prestação de serviço do profissional, que será avaliada pelo demandador. 
A etapa APRESENTAÇÃO de PROPOSTAS marca o fim da fase de levantamento de informações, as quais deverão ser transformadas em soluções através da apresentação de propostas ou anteprojetos (Ver Fig. № 05 - Etapa 04. Apresentação de propostas).

As propostas idealizadas para resolver os problemas de projeto apontados na etapa compreensão do problema e diagnóstico devem ser apresentadas para o cliente, discutidas e escolhida a proposta definitiva. Faz-se necessário que o profissional esteja munido de todas as informações necessárias, a fim de colaborar com os argumentos e proposições da solução pretendida. A participação do usuário é fundamental na avaliação geral do anteprojeto, visto que cada escolha realizada trará alguma consequência para o trabalho como um todo. Sugere-se capricho com os detalhes, organização do material, e principalmente clareza das informações. A escolha da proposta mais adequada, considerando as viabilidades técnica, estética, tempo e custo é o objetivo principal dessa etapa.

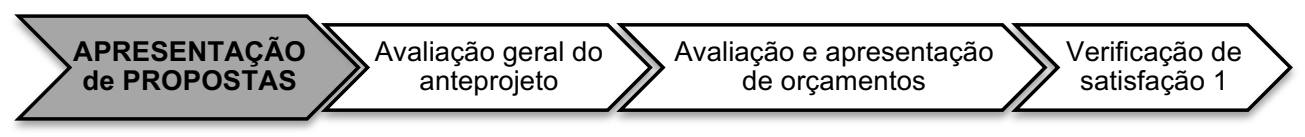

Fig. № 05 - Etapa 4 - Apresentação de propostas. Fonte: o autor.

A apresentação e aprovação de orçamento deve oferecer ao cliente a real noção de valores previstos a serem investidos na execução da obra. O profissional deverá apresentar uma planilha de custos que relacione todos os custos previstos com o projeto de design de interiores: registro e legalização; execução de obra civil; revisão e/ou instalação de estruturas elétricas, hidráulica, gás e lógica; iluminação (luminárias e luminotécnico); paisagismo; fornecedores principais: marcenaria, mobília, objetos decorativos e eletrodomésticos; prestadores de serviços e, sempre que necessários, serviços de consultoria. Os designers de interiores, com formação apenas em design de interiores, devem contar com a consultoria de arquitetos e engenheiros para as questões estruturais dos projetos.

Ao final dessa etapa, o profissional deverá identificar o grau de satisfação do cliente em relação ao anteprojeto definido, os orçamentos, bem como o conjunto de informações prestadas. A Verificação de satisfação 1 propõe que seja checado o nível de satisfação do usuário até esta etapa do trabalho. A ideia é verificar se há algo que não esteja completamente esclarecido, e que isso seja percebido e tratado. Ao realizar esta verificação antes do fechamento do projeto executivo final cria-se a possibilidade de corrigir possíveis desvios ou falhas que às vezes podem ocorrer.

A EXECUÇÃO DO PROJETO é a etapa que reúne todas as questões levantadas e tratadas, a proposta de anteprojeto escolhida e todas as informações complementares levantadas (Ver Fig. № 06 - Etapa 5 - Execução do projeto). Todo conjunto de informações será traduzido através do projeto executivo. Pode-se utilizar de forma análoga o esclarecimento prestado por Silva (1998, p.113) sobre o projeto executivo em arquitetura, que diz: "a finalidade do projeto executivo está expressa na própria denominação: ele serve como instrumento para a realização na obra, pressupondo a homologação da ideia exposta no anteprojeto." O projeto executivo deve ser considerado como "um sistema de instruções", que informarão todos os detalhes sobre a execução do projeto. Esta fase é composta por plantas, vistas e cortes desenhados em escala, com todas as informações técnicas de forma clara, especificando materiais e acabamentos definidos. 


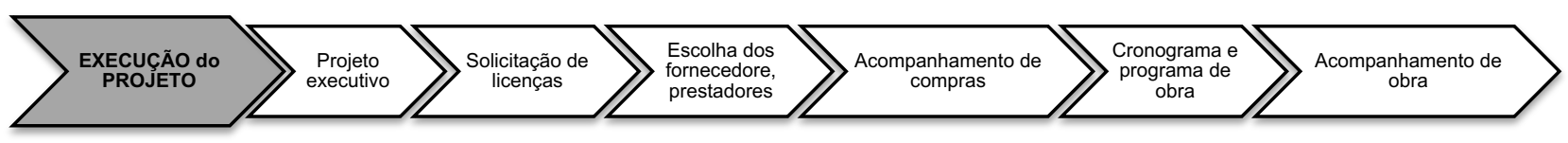

Fig. № 06 - Etapa 5 - Execução do projeto. Fonte: o autor.

Além das informações técnicas é necessário que o (1) projeto executivo seja complementado com as perspectivas - que proporcionam uma visão realista, na qual o espaço planejado é apresentado de forma tridimensional. $O$ início das atividades práticas para execução e implantação do projeto deve ser precedido da etapa (2) solicitação de licenças - em geral é necessário solicitar licenças para execução de obra. As demais etapas dependerão do deferimento de licença para início dos trabalhos. Os profissionais com formação em design ou design de interiores deverão recorrer a parcerias com arquiteto/engenheiro civil - estes são responsáveis legais para assinar laudo e/ou projeto executivo, solicitação de RRT (registro de responsabilidade técnica), quando o projeto envolver obra civil. (3) Escolha dos fornecedores e prestadores de serviços. O profissional de interiores comumente é cercado de fornecedores e prestadores de serviços das mais variadas atividades, a fim de atender à realização dos seus projetos. A relação de trabalho entre profissionais e fornecedores é pautada por profissionalismo e responsabilidade, visto que a eficiência ou não destes afetará diretamente o resultado do trabalho do contratado.

Definidos os fornecedores e prestadores de serviços, enquanto a execução civil da obra provavelmente está sendo executada, o profissional de interiores (4) acompanha compra de revestimentos, luminárias, mobília, eletrodomésticos, e outros materiais. Esta etapa deverá constar como uma das atividades de trabalho previstas descritas no contrato do profissional com o cliente. É válida a preparação de um plano de compras para garantir que os materiais, acabamentos, instalações, equipamentos e mobiliários estejam prontos no momento certo, os quais devem estar adequados à programação da obra. (5) A programação dos trabalhos ou cronograma de obra precisa ser realizada da forma mais verdadeira possível, considerando os prazos de cada fornecedor e a atuação coordenada de cada atividade. Deve ser considerado o tempo para realização de pedidos, fabricação, instalação e entrega.

Entende-se que o (6) acompanhamento de obra é uma etapa do trabalho do profissional de interiores que não pode ser opcional - este deve fazer parte do processo incondicionalmente para que os objetivos propostos sejam alcançados. Constitui-se de visitas constantes e regulares ao imóvel onde está sendo realizado o trabalho. Deve ser planejada com a frequência necessária de acordo com o nível de complexidade dos trabalhos e com a anuência do contrato previamente estabelecido com o cliente.

A última etapa do método de projeto de interiores é a VALIDAÇÃO FINAL (Ver Fig. № 07 Etapa 6 - Validação Final). Antes de realizar a entrega do ambiente com a obra executada e equipamentos e mobiliários instalados o profissional deverá fazer uma verificação geral de todo o trabalho. Evita-se através desse procedimento desagradáveis surpresas de algo que não esteja funcionando ou que não tenha sido executado corretamente. 


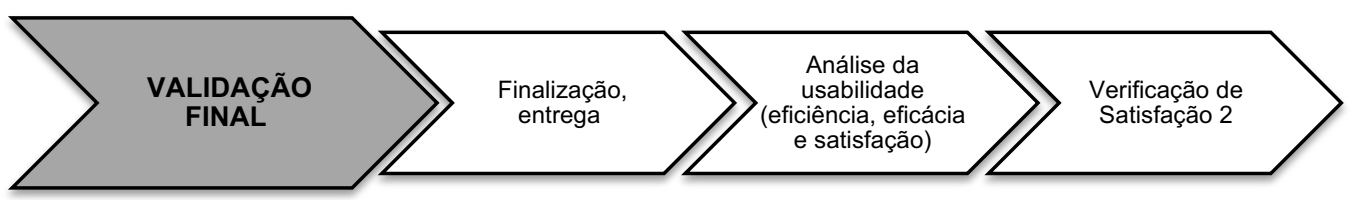

Fig. № 07 - Etapa 6 - Validação Final. Fonte: o autor.

$\mathrm{Na}$ (1) finalização e entrega, o profissional de interiores aproveita-se da oportunidade para defender seu projeto finalizado, falar sobre os benefícios da obra, soluções que irão proporcionar maior conforto e segurança para o cliente e as melhorias do ambiente em geral, agregando valor ao seu trabalho. É interessante que documentos como notas fiscais ou materiais que tratam de manutenção, limpeza e garantias sejam entregues nesse momento. Desta forma faz-se um fechamento dos trabalhos e passa-se segurança para o cliente sobre a manutenção do espaço a partir deste momento em diante.

A opinião do usuário após a conclusão dos trabalhos é de grande importância para o aprimoramento da atividade constantemente. Sendo assim, sugere-se que o profissional aplique um pequeno questionário sobre os (2) aspectos da usabilidade e (3) verificação de satisfação 2 , em relação aos ambientes edificados. O questionário deverá conter perguntas específicas sobre a eficiência, eficácia e grau de satisfação sobre cada cômodo em que realizou o trabalho. Essas informações ajudarão o profissional a mensurar qualitativamente o grau de satisfação dos seus trabalhos. Recomenda-se que o questionário deva ser respondido algumas semanas após o uso do espaço e sem a presença do profissional.

\section{Aspectos convergentes dos Métodos de projeto de Design e Design de Interiores}

É possível observar sobre os métodos apresentados neste conciso artigo que há uma estrutura geral predominante. Também consegue-se destacar algumas etapas (fases) que ocorrem com alguma frequência. O modelo predominante dicotômico de análise - síntese, foi apontado por Darke (1984), como a origem da maioria dos métodos em design na década de sessenta (com forte influência do campo das engenharias), este sofreu muitas variações e derivações, evoluindo para um modelo mais flexível - com possibilidades de loops e feedback (em cada fase), para um modelo predominante, como vemos que poderíamos resumir em: análise - síntese - geração - validação.

Observa-se que a ideia que predominou na primeira geração de metodólogos ainda influencia os métodos atuais, Lawson (2011) cita o trabalho realizado por Christopher Alexander em 1964, o qual considera a melhor expressão dessa primeira geração do pensamento sobre o processo de projeto (design process).8. "O método de Alexander consistia em listar todas as exigências de um problema específico de um projeto e depois procurar interações entre elas" (Alexander, 1964 apud Lawson, 2011, p. 79)." Nota-se que os métodos aqui apresentados, aplicam etapas que buscam identificar as necessidades e exigências do projeto, mesmo utilizando nomenclaturas diversas como: programação, coleta de dados, entrevista, observação em campo, compreensão do problema.

Vale destacar que o árduo trabalho de identificar o real problema de projeto igualmente permeia os dois campos estudados neste artigo. Lawson (2011, p. 116) é categórico em afirmar que

\footnotetext{
8 Importante apontar que o texto em sua língua original (inglês) trata de "design process", termo mais amplo. No Brasil, no livro de Lawson (2011), a expressão foi traduzida como "processo de projeto".
} 
uma das dificuldades em mapear o processo de projeto "é que nunca se sabe com certeza quando todos os aspectos do problema já foram revelados". Nesse sentido, embora os métodos auxiliem substancialmente os profissionais no desenvolvimento de projetos não podemos esperar por uma formulação completa e estática dos problemas de projeto. A relação destes com a solução, bem como sua melhor compreensão por parte dos segmentos envolvidos (designers, arquitetos, demandadores, usuários, fornecedores, etc.), será necessariamente algo complexo e naturalmente com possibilidades inesgotáveis de soluções.

A Geração de alternativas - também é uma etapa comum a todos os métodos e refere-se a geração de ideias e possibilidades de soluções. Esta etapa está intimamente ligada a etapa anterior de investigação de necessidades. Independentemente da demanda, seja ela um problema de design ou de arquitetura de interiores, se o problema foi compreendido com clareza fatalmente irá gerar soluções mais próximas das desejadas pelo profissional e o usuário. Muitos profissionais rejeitam a ideia de gerar várias alternativas e, principalmente, mostrá-las ao demandante. Teme-se que sejam feitas escolhas de várias alternativas impossíveis ou muito difíceis de combinar. Nesse sentido, é apreciado a colocação do arquiteto e engenheiro, Santiago Calatrava, citado por (Lawson 2011) que afirma: "Explorar alternativas em demasia é sinal de dúvida, pois no final terá de desenvolver uma solução única e deverá lutar para defender as ideias que a embasam". Contudo, Calatrava defende que para chegar a uma única ideia, se faz necessário concentrar esforços "em trabalhar apenas uma solução de cada vez". (Ibidem, p. 194-195)

As técnicas apontadas por Karlen (2008) na Metodologia de Planejamento, entrevista e observação de campo e a etapa coleta de dados, citada por Cross (2008), são técnicas que visam extrair do ambiente e do usuário (ou demandador do projeto) o máximo de informações possíveis para realização de um bom trabalho. Estas mesmas técnicas são indicadas no Método de Projeto de Interiores (Oliveira \& Mont'Alvão, 2016), quando os autores propõem técnicas mais robustas para investigação das necessidades do usuário, a saber: entrevista estruturada + uso de questionário (check-list), visita técnica-observação assistemática e análise da tarefa. O diferencial neste método é a ênfase dada ao uso destas técnicas conforme o método sugere - de forma mais precisa e estruturada, considerando-se uma fase precoce de planejamento e preparação para cada etapa. Neste sentido, o resultado das entrevistas, questionários, visita técnica e análise da tarefa, trarão ao profissional um nível mais acentuado de segurança na proposição de soluções.

\section{Considerações finais}

Projetar é um fenômeno complexo, multidimensional, multidisciplinar, onde a carga da experiência e do conhecimento do profissional faz toda diferença. Sabe-se que o processo, de forma natural, é constituído de etapas, ou fases, ou estágios, onde em cada momento da construção do trabalho haverá maior ou melhor habilidade por parte de quem executa.

Os aspectos convergentes entre o design industrial e o design interiores, revelam que os princípios de concepção dos métodos de projeto possuem origem semelhantes e que, de acordo com as especificidades de cada problema (ou do contexto) os processos metodológicos sofreram ajustes e derivações. Vale ressaltar que a complexidade dos problemas trazidos pelo usuário e, na maioria das vezes, a dificuldade em externar as questões do projeto - muitas vezes só compreendida lá na solução - são ingredientes que fazem desta atividade algo desafiador.

O Método de Projeto de Interiores (Oliveira \& Mont'Alvão, 2016) está em fase de testes com alguns escritórios de projeto de interiores. Em oportuno pretende-se apresentar novas revisões 
sobre o assunto. O contínuo estudo sobre a matéria agrega valor à área, e possibilita reflexões a fim de contribuir com possíveis melhorias nos atuais processos existentes.

\section{Referências}

ARCHER, L. B. Whatever became of design methodology. In CROSS, Nigel (org.) Developments in Design Methodology, Cross (org.) London: John Wiley \& Sons, 1984.

ARGAN, G. C. A História na Metodologia do Projeto. Revista Caramelo, no 6, p. 156-170. São Paulo, 1993.

BONSIEPE, G. Design: como prática de projeto. São Paulo: Blücher, 2012. 213p.

BROOKER, G. \& STONE, S. O que é design de interiores. Tradução: André Botelho. São Paulo: Senac, 2014. Título Original: What is interior design?

COELHO, L. A. (org.). Conceitos-chave em design. Rio de Janeiro: PUC - Rio, 2008.

CROSS, N. Engineering design methods. Strategies for product Design. 4th ed. London: John Wiley \& Sons, 2008.

DARKE, Jane. The primary generator and the design process. In: CROSS, Nigel (org.). Developments in Design Methodology. London: John Wiley \& Sons, 1984.

HIGGINS, I. Planejar espaços para o design de interiores. Tradução: Alexandre Salvaterra. São Paulo: G.Gilli, 2015. Título original: Spatial strategies for interior design.

KARLEN, Mark. Planejamento de espaços internos. Tradução: Alexandre Salvaterra. 3 ed. Porto Alegre: Bookman, 2010. Título original: Space Planning Basics

LAWSON, B. Como arquitetos e designers pensam. Tradução: Maria Beatriz Medina. 2ed. São Paulo: Oficina de textos, 2011. Titulo original: How designers think: the design process demystified.

OLIVEIRA, G. R. de; MONT'ALVÃO, Claudia Renata. O processo de projeto de interiores e o uso da ergonomia na prática segundo a visão de profissionais e usuários. Revista Ergodesign $\mathrm{HCl}$, [S.I.], v. 5, n. Especial, p. 61 - 72, jan. 2017. ISSN 2317-8876.

Oliveira, G. R. de; Mont'Alvão, Claudia; Revisão dos métodos de design industrial no final do século XX e o contexto sócio econômico brasileiro. p. 1331-1343. In: Anais do 12을 Congresso Brasileiro de Pesquisa e Desenvolvimento em Design [= Blucher Design Proceedings, v. 9, n. 2]. São Paulo: Blucher, 2016.

OLIVEIRA, G. R. de. Método de projeto de Interiores. Tese de doutorado. Pontifícia Universidade Católica do Rio de Janeiro - PUC - Rio, 2016.

ROOZENBURG, N. F. M. e EEKELS, J. Product Design: Fundamentals and methods. West Sussex, UK: John Wiley \& Sons, 1995.

SILVA, E. Uma introdução ao projeto arquitetônico. Porto Alegre: UFRGS, 1998.

VILLAROUCO, V. Construindo uma metodologia de avaliação ergonômica do ambiente - AVEA. Anais do 14을 Congresso Brasileiro de Ergonomia. Porto Seguro: ABERGO, 2008.

VILLAROUCO, V. Reflexões acerca da Ergonomia do Ambiente Construído. In: BOLETIM DA ASSOCIAÇÃO BRASILEIRA DE ERGONOMIA. Recife: ABERGO, 2007. 